\title{
Marginalization due to distance from schools
}

\author{
A. Lozano, F. Granados, R. Alarcón, A. Guzmán \& J. P. Antún \\ Engineering Institute, Universidad Nacional Autónoma de México, \\ Mexico
}

\begin{abstract}
This paper presents an analysis for identifying zones of high marginalization due to distance from schools. This distance is the length or time of the path between home and school, through the urban street network. We present a case of 4,500 public schools and nearly 1.3 millions of students, between 3 and 14 years old, within one of the regions of Mexico City. Children who demand public schools mainly belong to medium, high and very high sectors of socioeconomic marginalization. Spatial analysis was used for identifying the straight line covering of schools, and network analysis was used for obtaining main flows and estimating travelled length and time. The results let us identify sub-zones where the highest marginalization due to distance from schools is presented; and to detect some reasons for such a marginalization. Then, for a sub-zone, the trip characteristics were analyzed, and school bus service paths were proposed for certain types of trips.
\end{abstract}

Keywords: marginalization, distance, paths.

\section{Introduction}

Inside Distrito Federal (DF), one of the two regions of Mexico City, nearly 4,500 public kindergartens, elementary schools and high schools (basic levels) are located in 2,675 properties [1]. They have registered over 1.3 million children between 3 and 14 years old (see table 1). The government expects that these public schools serve the demanding population, i.e., approximately $76 \%$ of the total such age population, which suffer very high, high, medium and low (30\%), socioeconomic marginalization $[2,3]$.

However, registered children do not coincide with the demanding population, as shown in table 1; there is a deficit for kindergarten education, while there is a surplus for the other two levels. On one hand, kindergarten public education is 
not enough to satisfy the demanding population (see table 2), which means that no covered children could go to private schools or they could not go to school at all (which is very worrying); figure 1 shows the location of supply and demand of kindergarten education. On the other hand, children from the other region probably go to schools inside Distrito Federal, and they have to travel a great deal.

Hence some children suffer marginalization due to distance from schools, additional to socioeconomic marginalization. In order to reduce the former kind of marginalization, it is necessary to identify the location of the longest trips for going to school.

\section{Straight line covering of schools}

The recommended urban service radius (USR) for each scholar level is shown in table 3 [4]. If this radius is drawn, it would seem that the majority of the demand centroids are covered, as shown in figure 2. However, this result is unreal because it represents a situation where the capacity of each school is always enough to serve the children inside its coverage area.

Then, we obtained straight line distances between demand centroids and schools, considering that children go to the nearest school and each school has enough capacity. The results are shown in table 3. Average straight distances are lower than recommended distances, but maximum distances are higher than recommended distances. This situation is optimistic, because children could not go to the nearest school and, instead of travelling in a straight line they have to use the streets network, which is sparse in some zones and congested everywhere.

\section{Distances and times travelled and student flows}

In order to represent a more realistic situation, school capacity was taking into account and it was supposed that students travel (between demand centroids and schools) through the main streets and arteries network during rush hour. Travel times at rush hour were obtained by using a user equilibrium model, which was presented in a previous paper [5].

We used a network analysis for identifying main flows and estimating travelled lengths and times. Specifically, a Transportation Model was used, where the demanding population at centroids and capacity of schools indicated supply and demand, respectively. The objective function was to minimize total travelled length or time through the urban streets network. For kindergarten education, just the served children were considered, assuming that they belonged to high and very high sectors of socioeconomic marginalization (see table 2). Instead, for elementary and high school education, fictitious demand points were located in the other region to represent children who do not live within Distrito Federal but go to school there. The results are shown in table 4 and figures 3 and 4. 
Table 1: Registered children vs. demanding population.

\begin{tabular}{|l|r|r|r|}
\hline \multicolumn{1}{|c|}{ Level } & $\begin{array}{c}\text { Demanding } \\
\text { population }\end{array}$ & $\begin{array}{c}\text { Registered } \\
\text { children }\end{array}$ & \multicolumn{1}{c|}{$\begin{array}{c}\text { Surplus (+) or } \\
\text { deficit }(-)\end{array}$} \\
\hline Kindergarten & 321,001 & 188,792 & $-132,209$ \\
Elementary school & 617,988 & 782,644 & 164,656 \\
High school (basic levels) & 320,234 & 398,940 & 78,706 \\
\hline Total & $1,259,223$ & $1,370,376$ & \multicolumn{1}{|r}{} \\
\cline { 1 - 2 } & &
\end{tabular}

Table 2: $\quad$ Served children according to socioeconomic marginalization.

\begin{tabular}{|c|c|c|c|c|c|c|}
\hline \multirow{2}{*}{ Level } & \multirow{2}{*}{$\begin{array}{l}\text { Registered } \\
\text { children }\end{array}$} & \multicolumn{5}{|c|}{$\begin{array}{l}\text { Served population (\%) according to } \\
\text { socioeconomic marginalization }\end{array}$} \\
\hline & & $\begin{array}{l}\text { Very } \\
\text { Low }\end{array}$ & Low & Medium & High & $\begin{array}{l}\text { Very } \\
\text { High }\end{array}$ \\
\hline Kindergarten & 188,792 & $0 \%$ & $0 \%$ & $0 \%$ & $57 \%$ & $100 \%$ \\
\hline $\begin{array}{l}\text { Elementary } \\
\text { school }\end{array}$ & 782,644 & $0 \%$ & $30 \%$ & $100 \%$ & $100 \%$ & $100 \%$ \\
\hline $\begin{array}{l}\text { High school } \\
\text { (basic levels) }\end{array}$ & 398,940 & $0 \%$ & $30 \%$ & $100 \%$ & $100 \%$ & $100 \%$ \\
\hline Total & $1,370,376$ & & & & & \\
\hline
\end{tabular}

Table 3: $\quad$ Urban service radius and straight line distances.

\begin{tabular}{|l|c|c|r|r|}
\hline \multirow{2}{*}{\multicolumn{1}{|c|}{ Level }} & \multicolumn{2}{|c|}{$\begin{array}{c}\text { Urban service } \\
\text { radius }\end{array}$} & $\begin{array}{r}\text { Straight line distances } \\
(\mathrm{km})\end{array}$ \\
\cline { 2 - 5 } & $\mathrm{km}$ & minutes & Maximum & \multicolumn{1}{c|}{ Average } \\
\hline Kindergarten & 0.75 & 15 & 1.27 & 0.37 \\
Elementary school & 0.50 & 15 & 1.50 & 0.31 \\
High school (basic levels) & 1.00 & 15 & 1.48 & 0.49 \\
\hline
\end{tabular}

The average length is very high for all of the scholar levels: it goes from 2.7 to 6.4 times the recommended length (USR) (see table 4). This means that students have to travel a great deal to reach their school. Trips are even longer for some students who live in some zones (outskirts) where the urban streets network is very sparse, and for students who live in the other region (called Edo. Mexico).

Also, the average time is very high compared with the recommended USR, which is 15 minutes for all the scholar levels. Travel times are extremely high for elementary and high school (see table 4).

Therefore, average trips of students are very long, longer that the recommended ones; which implies that students suffer marginalization due to distance from schools. 


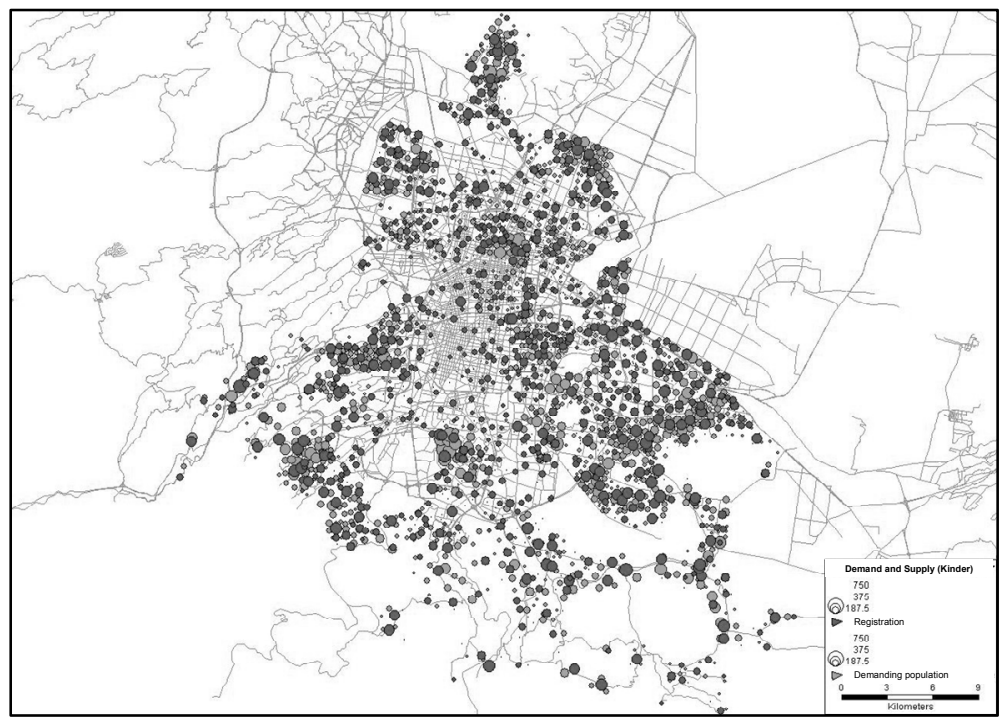

Figure 1: Demand and supply of kindergarten education.

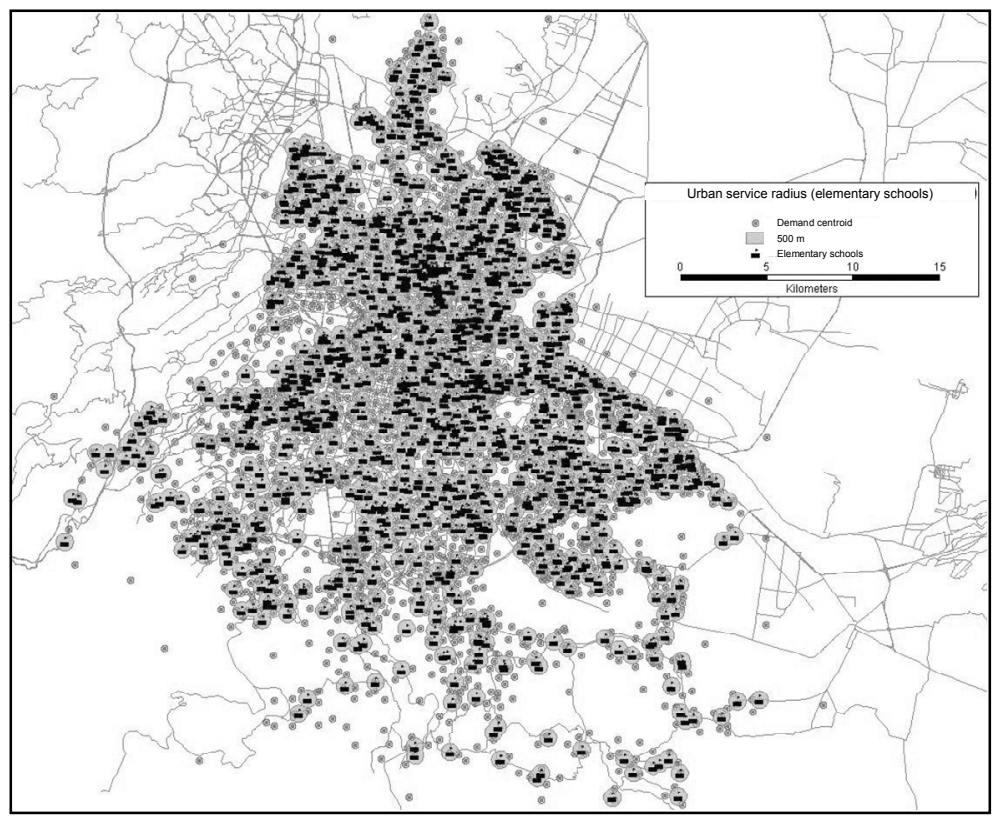

Figure 2: Urban service radius of elementary schools and locations of demand centroids. 
Table 4: $\quad$ Distance and time of trips between schools and demand centroids.

\begin{tabular}{|l|c|c|c|c|}
\hline \multicolumn{1}{|c|}{ Level } & $\begin{array}{c}\text { Average } \\
\text { length }\end{array}$ & $\begin{array}{c}\text { Difference } \\
\text { vs. USR }\end{array}$ & $\begin{array}{c}\text { Average } \\
\text { time }\end{array}$ & $\begin{array}{c}\text { Difference } \\
\text { vs. USR }\end{array}$ \\
\hline Kindergarten & $2.80 \mathrm{~km}$ & $273 \%$ & $\begin{array}{c}19 \mathrm{~min} \\
1 \mathrm{hr}\end{array}$ & $27 \%$ \\
Elementary school & $3.72 \mathrm{~km}$ & $644 \%$ & $\begin{array}{c}55 \mathrm{~min} \\
2 \mathrm{hr}\end{array}$ & $667 \%$ \\
High school (basic levels) & $3.80 \mathrm{~km}$ & $280 \%$ & $13 \mathrm{~min}$ & $787 \%$ \\
\hline
\end{tabular}

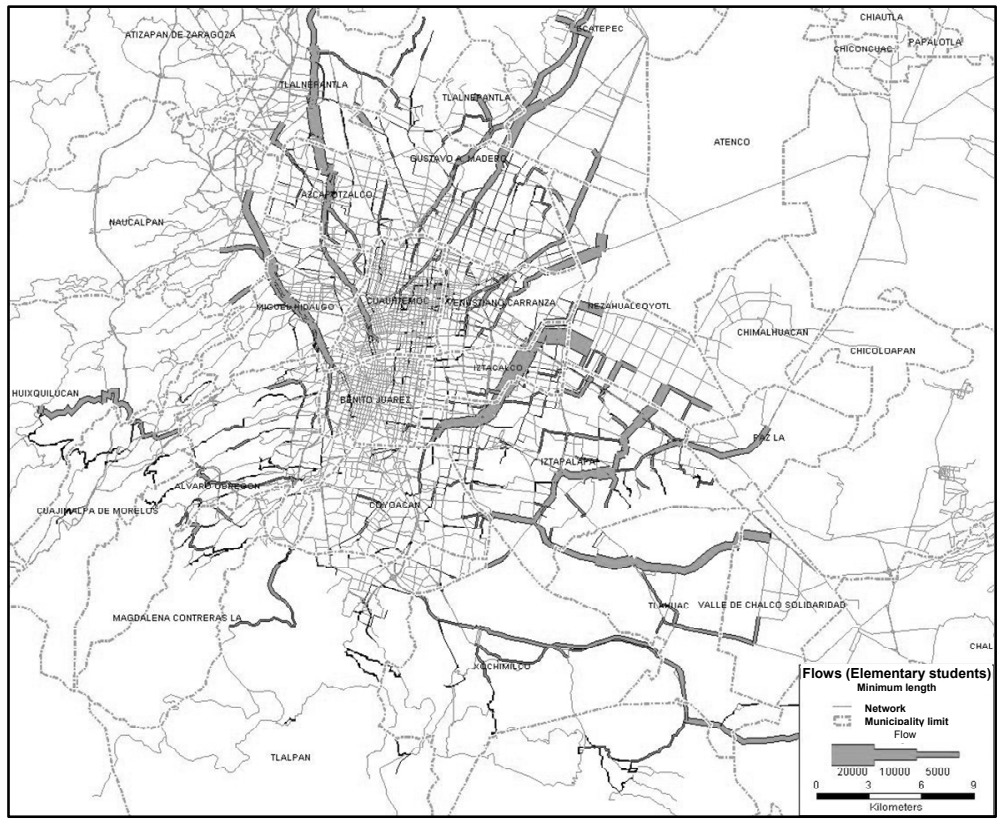

Figure 3: $\quad$ Flow on the urban network.

An interesting find is that, the urban area of the other region, which is adjacent to DF on the north and east sides, influences marginalization of DF. As example, figure 3 shows the main minimum length flows between demand centroids and elementary schools. Marginalization due to school distances is mainly located in the east and north outskirts of DF, and in the other region; instead, south and west outskirts present marginalization, but this is not so grave.

Figure 4 shows schools, demand centroids and minimum length trips. Schools are not located where demanding population exists; hence students have to make long trips along the congested urban streets network. Many schools are located downtown, where few students inhabit, while students are concentrated in some zones in the outskirts, where there are not enough schools. 


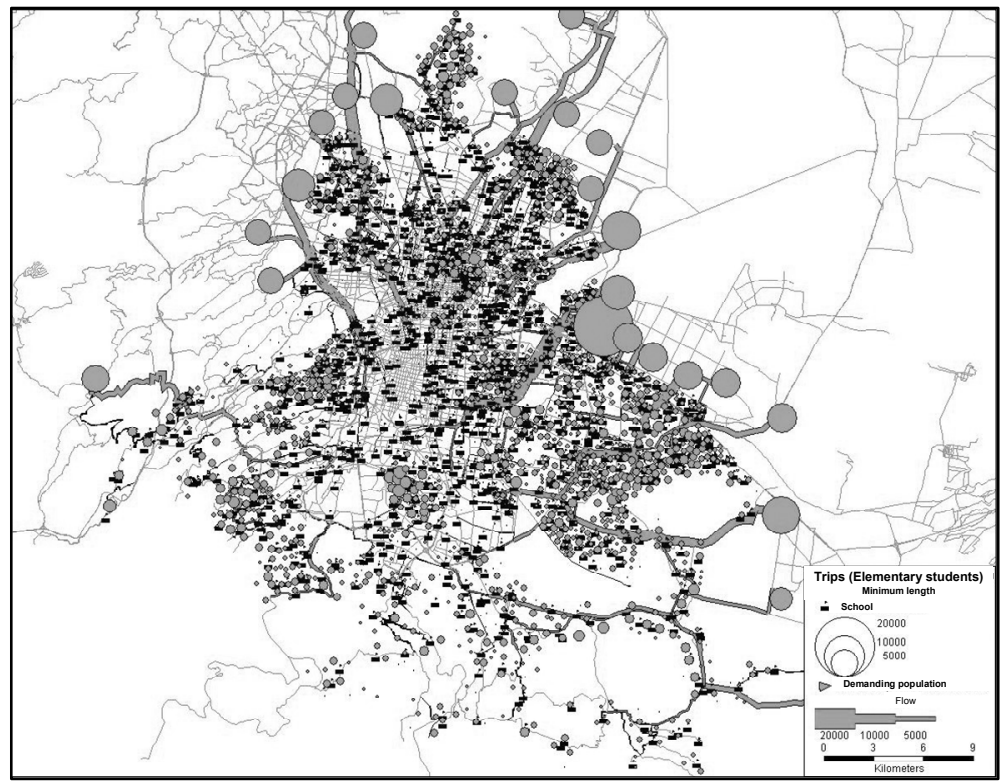

Figure 4: $\quad$ Schools, demand and minimum length trips.

Therefore, a recommendation could be to build more schools in the outskirts; however it takes time and could not be possible in some zones. Some neighbourhoods do not have available plots or are inside risk areas where is forbidden to built.

\section{Marginalization in a sub-zone of DF}

It is very important to reduce marginalization due to distance from schools as much as possible by means of actions on the short and long times.

In order to know more about marginalization due to distance from schools, a sub-zone (on the southwest part of the DF) was chosen for a detailed analysis. A sample of 50 schools was chosen, and their students addresses where obtained; hence students trips were analyzed. An example of trips between schools and points into neighbourhoods are shown, as desire lines, in figure 5. There are many short trips, which represent children going to the nearest school, but also there are many long trips which represent children travelling several kilometres. In the sub-zone, the travelled length has an average of $5.79 \mathrm{~km}$ (for elementary school).

Short trips do not indicate marginalization due to school distance, but the rest of the trips (which are over the recommended distances) indicate some grade of marginalization.

Long trips are distributed everywhere inside the sub-zone; there are not exclusively into certain areas (as we initially thought). Hence, marginalization due to school distance is presented everywhere inside the sub-zone. In fact, children do not go to the nearest school, even when it has enough capacity. The 
marginalization could be due to: a) there are not enough near schools or the capacity of near schools is not enough; b) students prefer schools located near their parents job; and c) student prefer other schools because the quality of near schools is not good enough.

Student of the sub-zone prefer school which are located over the city centre and near main arteries. The most longest and frequent trips are shown in figure 6 .

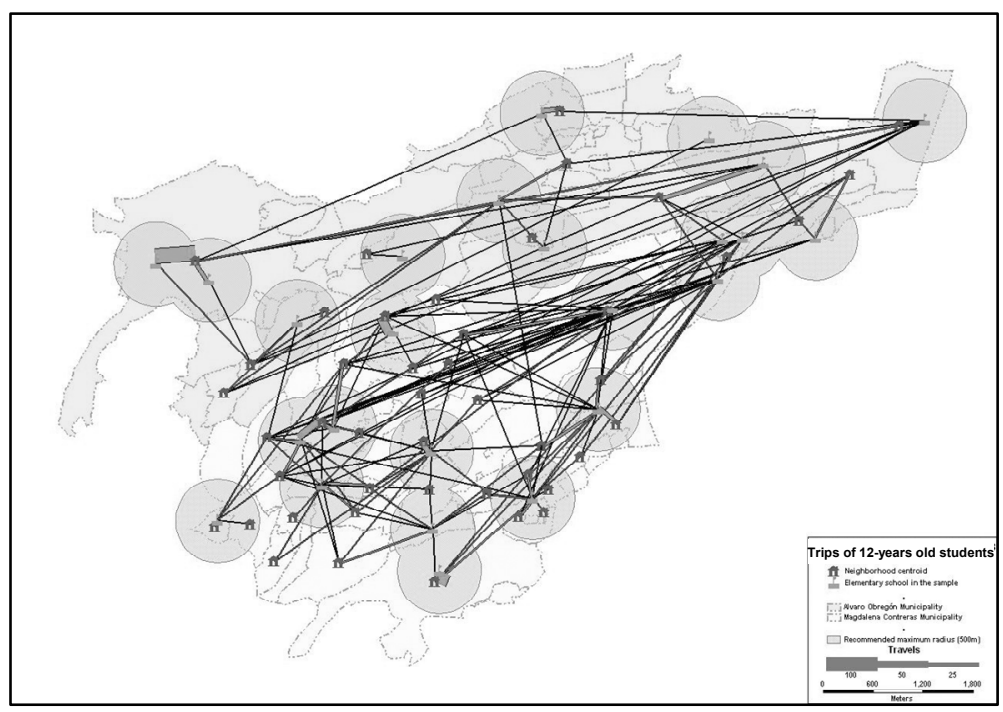

Figure 5: Students' trips in a sub-zone.

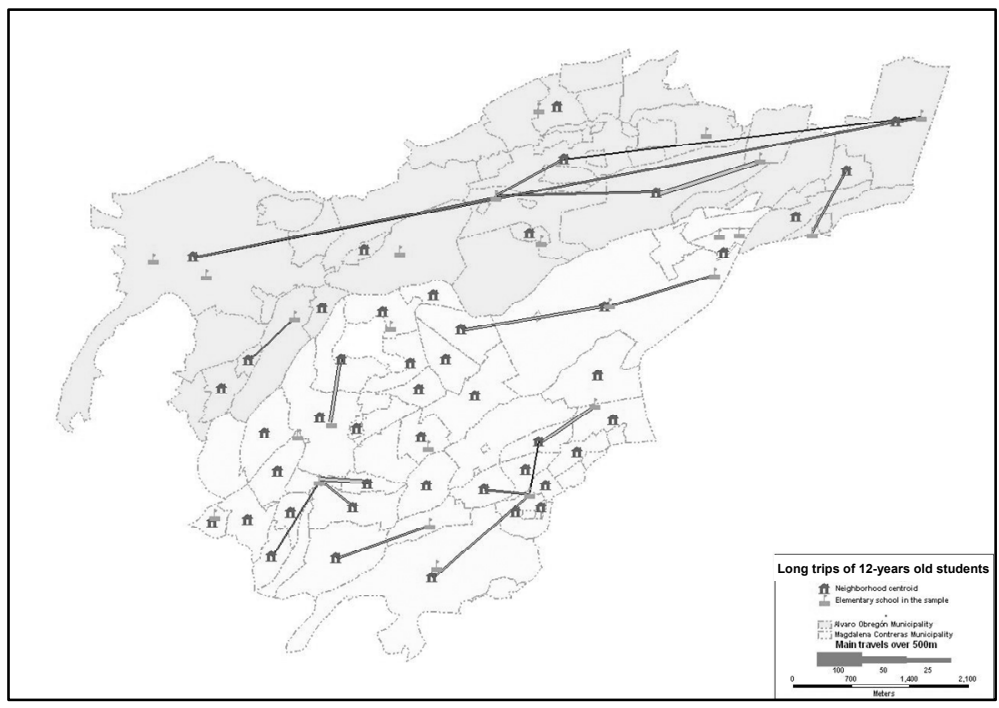

Figure 6: Long trips in a sub-zone. 


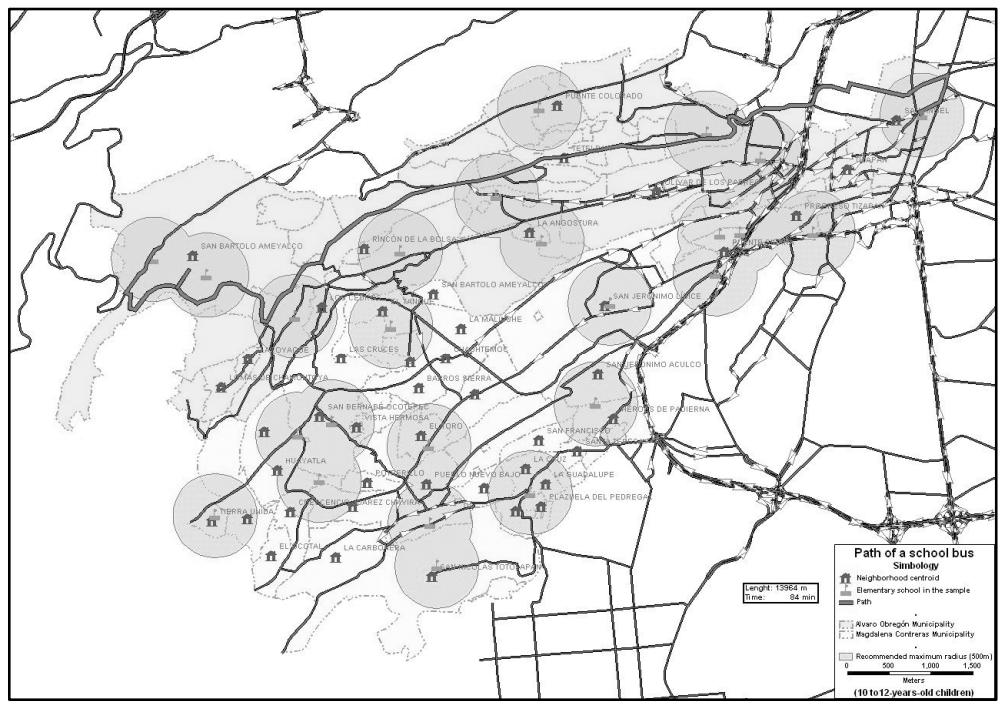

Figure 7: $\quad$ Path of a school bus service.

We can distinguish two types of long trips, as follows: a) children from certain neighbourhoods (located in the central part of the sub-zone) assist to the nearest school, but it is farer than the recommended distance; and b) some children from west neighbourhoods do not go to the nearest school due to some other reasons.

Given that the network is very sparse inside this sub-zone, there are few or sometimes unique paths between each neighbourhood-school pair. We obtained the shortest paths between each neighbourhood-school pair, considering more than one stop for some neighbourhoods. Paths were obtained solving a vehicle routing problem. These paths minimize the travelled time through the congested streets and arteries network. Figure 7 shows the path for the longest trip inside the sub-zone. For the most frequent trips, a small bus could be assigned to each path, with two stops within the neighbourhood. In the majority of the neighbourhoods of this sub-zone, there are very many narrow streets which does not let to pickup children at home. Hence, we propose one or two points (for example squares or parks) in each neighbourhood, where to pickup children.

The main paths characteristics are the following:

a) Some paths are very long. For example, path in figure 7 is $13.96 \mathrm{~km}$ long and last 85 minutes. Even when a school bus service is available, these trips exceed a lot the recommended distance and time. Hence it is necessary to increase the capacity of the schools located in the west part of the sub-zone, and/or improving the quality of the existent ones.

b) Some paths are long, but a school bus service could help to reduce travelled length and time (because currently, children could take more than one public bus and make transfers). These trips could exceed a tolerable percentage, the recommended length and time. 
c) Some paths are not so long, so a school bus service could help to reduce travelled length and time under the recommendations.

\section{Conclusions}

The identification of the zones with high marginalization due to distance from schools can allow the resources canalization to these zones.

In the Distrito Federal (an in the whole Mexico City), more schools must be constructed, but in the mean time a school bus transportation service could be implemented in some zones, for some kinds of trips.

We found that the other region of Mexico City influences the marginalization due to distance from schools in the Distrito Federal, but also that more scholar infrastructure is required in the outskirts. Also, we found that children do not go to the nearest school due to several reasons.

A sub-zone was chosen, and a set of routes were proposed for some trips, in order to bring near students to their schools by means of a school bus transportation service.

The problem magnitude is so large, such that additional measures are required.

Finally, an interesting result is that a spatial analysis considering straight line distances is not enough to analyse marginalization due to distance from schools in an urban area. A network analysis let us to represent more realistic situations in an urban environment, and gives us a better understanding of the problem.

\section{References}

[1] GDF., Database of schools and properties in the DF. Ministry of Education, Government of Distrito Federal (GDF), Mexico, 2008.

[2] GDF., Database of socioeconomic and marginalization of DF. Government of Distrito Federal (GDF), Mexico, 2006.

[3] INEGI., II Census of population and housing 2005, National Institute of Geography and Informatics (INEGI), Mexico, 2005.

[4] SEDESOL., Normative system of urban equipment, Ministry of Social Development of the Federal Government (SEDESOL), Mexico, 1995. In Spanish.

[5] Lozano, A., F. Granados, J. P. Antún., Estimation of Vehicle Flows and Emissions, for Several Scenarios of Street Network Modifications, in Mexico City. American Journal of Environmental Sciences, 4(3), 2008. 